\title{
Fallo del III Premio de Teatro Latinoamericano George Woodyard (2008)
}

Un jurado integrado por Jean Graham-Jones (City University of New York), Gail Bulman (Syracuse University) y William García (Union College) decidió otorgar el III Premio Teatral George Woodyard (2008) a la obra Noche cubana después de una deliberación sobre 9 obras seleccionadas entre las 104 concursantes. Noche cubana fue presentada bajo el seudónimo "Max," cuyo autor, una vez abierto el sobre sellado, resultó ser el cubano José Luís García-Rodríguez. Los tres miembros del jurado observaron que la "pieza brilla por su humor, diálogos dinámicos, energía y un ritmo sólido." El jurado también destacó el excelente modo en que la pieza juega con la tradición del sainete y del bufo cubano desde una perspectiva contemporánea y postmoderna. La obra será publicada en el próximo número de primavera (2009) de Latin American Theatre Review.

José Luís García-Rodríguez, nació en la ciudad de Holguín, al norte de la región oriental de Cuba, el 26 de octubre de 1955. Periodista, narrador y dramaturgo. Actualmente se desempeña como realizador de programas radiales, dedicados a investigar la música cubana e internacional. Tiene publicados los libros Los silencios del ruiseñor (cuentos), El hombre de los guantes amarillos (teatro), Apuntes de un cazador (cuentos) y Una crónica de amor (teatro). Entre sus otras obras de teatro se encuentran Ensayo general, El robo del elefante blanco, Crónica de los viejos amantes, Una noche de cine francés, La ayuda, A la media noche, Primer amor y otros pesares. Todas estas obras han sido llevadas al escenario entre 1983 y la actualidad por agrupaciones cubanas y españolas. José Luís ha sido laureado por Casa de las Américas. Por sus obras teatrales y narrativas ha recibido en cuatro ocasiones el Premio de la Ciudad (1992 - dos veces, 1993 y 1998), este es el máximo galardón artístico que se concede en Holguín. También recibió el Premio Nacional de Cuento Regino Boti en 1996, por su libro Ejercicios para regresar.

Laurietz Seda

Fundadora del Premio Teatral George Woodyard 